\title{
Structural studies on the lipopolysaccharide core of Proteus OX strains used in Weil-Felix test: a mass spectrometric approach
}

\author{
Anna N. Kondakova, ${ }^{\mathrm{a}, \mathrm{b}}$ Evgeny Vinogradov, ${ }^{\mathrm{c}}$ Buko Lindner, ${ }^{\mathrm{b}}$ Yuriy A. Knirel, ${ }^{\mathrm{a}, *}$ \\ Ken-ichi Amano ${ }^{\mathrm{d}}$ \\ ${ }^{a}$ N.D. Zelinsky Institute of Organic Chemistry, Russian Academy of Sciences, Leninsky Prospekt 47, 119991 Moscow, Russian Federation \\ ${ }^{\mathrm{b}}$ Research Center Borstel, Center for Medicine and Biosciences, 23845 Borstel, Germany \\ ' Institute for Biological Sciences, National Research Council, Ottawa ON, Canada K1A OR6 \\ ${ }^{d}$ Central Research Laboratory, Akita University, School of Medicine, 1-1-1 Hondo, Akita 010, Japan
}

Received 28 March 2003; accepted 25 June 2003

\begin{abstract}
The core region of the lipopolysaccharides of Proteus group OX bacteria, which are used as antigens in Weil-Felix test for serodiagnosis of rickettsiosis, were studied by chemical degradations in combination with ESI FTMS, including infrared multiphoton dissociation (IRMPD) MS/MS and capillary skimmer dissociation. Structural variants of the inner core region were found to be the same as in Proteus non-OX strains that have been studied earlier. The outer core region has essentially the same structure in Proteus vulgaris OX19 (serogroup O1) and OX2 (serogroup O2) and a different structure in Proteus mirabilis OXK (serogroup O3). A fragmentation due to the rupture of the linkage between GlcN or GalN and GalA was observed in IRMPD-MS/MS of core oligosaccharides and found to be useful for screening of Proteus strains to assign structures of the relatively conserved inner core region and to select for further studies strains with distinct structures of a more variable outer core region.
\end{abstract}

(C) 2003 Elsevier Ltd. All rights reserved.

Keywords: Lipopolysaccharide; Core structures; ESI FT-MS; IRMPD-MS/MS; Weil-Felix test; Proteus OX

\section{Introduction}

Since 1916, Proteus group OX strains were used in Weil-Felix test ${ }^{1}$ for serodiagnosis of rickettsiosis, a group of diseases that is caused by bacteria of the genus Rickettsia ${ }^{2}$ and poses serious medical problems in both

Abbreviations: CSD, capillary skimmer dissociation; FTMS, Fourier transform mass spectrometry; gHMBC, gradientselected heteronuclear multiple-bond correlation; IRMPD, infrared multi-photon dissociation; LPS, lipopolysaccharide; anhMan, 2,5-anhydromannose; Ara4N, 4-amino-4-deoxy-Larabinose; Hep, L-glycero-D-manno-heptose; DDHep, Dglycero-D-manno-heptose; GalAPu and GalASp, amides of GalA with butane-1,4-diamine (putrescine) and 4-azaoctane1,8-diamine (spermidine), respectively; Kdo, 3-deoxy-Dmanno-oct-2-ulosonic acid; PEtn, 2-aminoethyl phosphate.

* Corresponding author. Tel.: +7-095-9383613; fax: +7095-1355328.

E-mail address: knirel@ioc.ac.ru (Y.A. Knirel). developing and developed countries. ${ }^{3}$ The test is based on the ability of sera from patients infected with various rickettsial agents to react with Proteus OX cells. Sera from patients infected with typhus group Rickettsiae agglutinate cells of Proteus vulgaris OX19 (typhus and Rocky Mountains spotted fever) or P. vulgaris OX2 (spotted fevers except for Rocky Mountains spotted fever). Antibodies from patients with scrub typhus caused by Orientia tsutsugamushi (former Rickettsia tsutsugamushi) bind Proteus mirabilis OXK cells. Multiple studies demonstrated that the lipopolysaccharide (LPS) is responsible for the serological cross-reactivity that underlies Weil-Felix test (Refs. ${ }^{4-7}$ and references cited therein).

Based on the LPS, Proteus strains have been classified in more than 60 serogroups, ${ }^{8,9}$ and the group OX strains are included in the first three serogroups: O1 for $P$. vulgaris OX19, $\mathrm{O} 2$ for $P$. vulgaris $\mathrm{OX} 2$ and $\mathrm{O} 3$ for $P$. mirabilis OXK. The serospecificity of Proteus is defined by both the O-polysaccharide chain and the outer core 
region of the LPS, ${ }^{10}$ the latter being almost as high structurally variable as the former. ${ }^{11}$ Serological crossreactivity of strains belonging to different serogroups is rather common in Proteus and could be substantiated by sharing epitopes on both O-polysaccharide and core. $^{10}$

Aiming at the understanding of the molecular basis of the serospecificity and cross-reactivity of Proteus OX strains, including cross-reactivity with anti-rickettsial sera, we have established structures of the O-polysaccharides of $P$. vulgaris OX19, $P$. vulgaris OX2 and $P$. mirabilis OXK. ${ }^{12}$ In this paper, we report on elucidation of the LPS core structures of group OX strains and, for comparison, that of $P$. mirabilis S1959, which belongs to the same $\mathrm{O} 3$ serogroup as $P$. mirabilis OXK. The structures of the core of $P$. vulgaris $\mathrm{OX} 2^{13}$ and $P$. mirabilis $\mathrm{S} 1959^{14}$ have been reported previously and are confirmed in this work.

\section{Experimental}

\subsection{Bacterial strains, growth and isolation of lipopolysaccharides}

P. vulgaris $\mathrm{OX} 2(\mathrm{Jpn})$ and $\mathrm{OX19}(\mathrm{Jpn})$, P. mirabilis OXK (Jpn) were from the National Institute of Infectious Diseases (Tokyo, Japan). P. vulgaris PrO 8/44 (OX2) and O8 were from the Czech National Collection of Type Cultures (CNCTC, Prague), and P. vulgaris OX19 (ATCC 6380) from the American Type Culture Collection (Rockville, MD, USA). P. mirabilis S1959, its R-mutant $P$. mirabilis R110 that is devoid of the Opolysaccharide chain but contains the full LPS core, and $P$. penneri strains were from the collection of the Institute of Microbiology and Immunology (University of Lodz, Lodz, Poland).

Bacteria were cultivated under aerobic conditions in tryptic soy broth (OX strains) or nutrient broth supplemented with $1 \%$ glucose (P. mirabilis 1959 and R110), harvested, centrifuged, washed several times with water and lyophilised.

The LPSs were isolated from $\mathrm{S}$ type Proteus strains by the phenol-water method ${ }^{15}$ and from $P$. mirabilis R 110 by the phenol- $\mathrm{CHCl}_{3}$ - petroleum ether method. ${ }^{16}$ The LPS samples were purified by ultracentrifugation as described. ${ }^{17}$

\subsection{Sera, SDS-PAGE and immunoblotting}

The covalescent sera from patients with murine typhus, Japanese spotted fever and scrub typhus were prepared as described previously. ${ }^{18-20}$

SDS-PAGE and immunoblotting were performed essentially as described. ${ }^{21,22}$ The purified LPS samples were dissolved in sample buffer at a concentration of 0.1 $\mathrm{mg} \mathrm{mL} \mathrm{L}^{-1}$. The LPS $(0.5 \mu \mathrm{g}$ of each) was applied to a $12.5 \%(\mathrm{w} / \mathrm{v})$ polyacrylamide gel and resolved by electrophoresis. The LPS profile on the gel was developed by silver staining. ${ }^{23}$

For immunoblotting, the LPS samples were transferred from the gel to a polyvinylidene difluoride membrane (Nihon Millipore, Japan), which was incubated with appropriately diluted human sera as the primary antibody. Horseradish peroxidase-conjugated goat anti-human IgG (Dako, Denmark) was used as the secondary antibody. The bound antibody was detected with 3,3'-diaminobenzidine.

\subsection{Degradations of lipopolysaccharides}

2.3.1. Mild acid degradation. The LPS from each strain (20-100 mg) was hydrolysed with $2 \% \mathrm{AcOH}\left(100{ }^{\circ} \mathrm{C}, 4\right.$ h). The resulting precipitate was removed by centrifugation (3000 r.p.m., $30 \mathrm{~min}$ ), and the core oligosaccharides were isolated from the supernatant by GPC on a column $(80 \times 2.5 \mathrm{~cm})$ of Sephadex G-50 (S) (Amersham Biosciences, Sweden) using pyridinium acetate buffer $(4 \mathrm{~mL}$ $\mathrm{Py}$ and $10 \mathrm{~mL}$ glacial $\mathrm{AcOH}$ in $1 \mathrm{~L}$ water) as the eluant and a Waters differential refractometer (USA) for monitoring. The oligosaccharides were reduced with $\mathrm{NaBH}_{4}$ in water, desalted by GPC on a column $(70 \times$ $1.6 \mathrm{~cm}$ ) of Sephadex G-15 (Amersham Biosciences, Sweden) in the same buffer and purified by anionexchange chromatography on a $5 \mathrm{~mL}$ column of HiTrap $\mathrm{Q}$ (Amersham Biosciences, Sweden) in a gradient of $0 \rightarrow$ $1 \mathrm{M} \mathrm{NaCl}$ over $1 \mathrm{~h}$ at a flow rate $3 \mathrm{~mL} \mathrm{~min}^{-1}$ to give oligosaccharides $\mathbf{1}$. The products from $P$. vulgaris OX19 were further fractionated by cation-exchange chromatography on a $5 \mathrm{~mL}$ column of HiTrap S (Amersham Biosciences, Sweden) in a gradient of $0 \rightarrow 1 \mathrm{M} \mathrm{NaCl}$ over

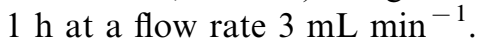

2.3.2. O-Deacylation. The LPS from each strain $(20 \mathrm{mg})$ was treated with anhydrous hydrazine $(1 \mathrm{~mL})$ for $1 \mathrm{~h}$ at $50{ }^{\circ} \mathrm{C}$. The cooled mixture was poured into stirred acetone $(200 \mathrm{~mL})$, the precipitated material was collected by centrifugation and purified by GPC on Sephadex G-50 (S). The fractions were lyophilised to yield O-deacylated LPS 2.

2.3.3. Deamination. The LPS from $P$. mirabilis $\mathrm{OXK}$ $(100 \mathrm{mg})$ was dissolved in water $(20 \mathrm{~mL})$ and $\mathrm{NaNO}_{2}$ $(100 \mathrm{mg})$ and conc AcOH $(1 \mathrm{~mL})$ were added. After $3 \mathrm{~h}$ at $25^{\circ} \mathrm{C}$, the lipid was removed by ultracentrifugation $(120,000 \mathrm{~g}, 2 \mathrm{~h})$. The target tetrasaccharide $\mathbf{3}$ was isolated from the supernatant by GPC on Sephadex G-50 and purified by reverse-phase high-performance liquid chromatography (HPLC) on a column $(25 \times 1$ $\mathrm{cm}$ ) of Aqua C18 (Phenomenex, USA) in water with monitoring by a Gilson model 151 UV detector (France) at $220 \mathrm{~nm}$. 


\subsection{Chemical analyses}

For monosaccharide analysis, a sample $(1 \mathrm{mg})$ was hydrolysed with $4 \mathrm{M} \mathrm{CF}_{3} \mathrm{CO}_{2} \mathrm{H}\left(100{ }^{\circ} \mathrm{C}, 2 \mathrm{~h}\right)$, dried under a stream of nitrogen and reduced with $\mathrm{NaBH}_{4}$ or $\mathrm{NaBD}_{4}$. After adding glacial $\mathrm{AcOH}$ and $\mathrm{MeOH}(2 \times 1$ $\mathrm{mL})$, the sample was dried, acetylated with $\mathrm{Ac}_{2} \mathrm{O}(0.5$ $\mathrm{mL}, 100{ }^{\circ} \mathrm{C}, 20 \mathrm{~min}$ ), dried and analysed be GLC-MS on an HP Ultra 1 column $(25 \mathrm{~m} \times 0.3 \mathrm{~mm})$ using a Varian Saturn 2000 ion-trap instrument (USA). Methylation was performed as described, ${ }^{24}$ the methylated substance was recovered by extraction using a $\mathrm{CHCl}_{3}-$ water system, and the partially methylated alditol acetates were prepared and analysed as described above.

\subsection{Instrumental methods}

2.5.1. NMR spectroscopy. ${ }^{1} \mathrm{H}$ and ${ }^{13} \mathrm{C}$ NMR spectra were recorded using a Varian UNITY/Inova 500 spectrometer (USA) for $\mathrm{D}_{2} \mathrm{O}$ solutions at $25^{\circ} \mathrm{C}$ with acetone as internal standard $\left(\delta 2.225\right.$ for ${ }^{1} \mathrm{H}$ and 31.5 for $\left.{ }^{13} \mathrm{C}\right)$ using standard pulse sequences COSY, TOCSY (mixing time $120 \mathrm{~ms}$ ), NOESY (mixing time $300 \mathrm{~ms}$ ), ${ }^{1} \mathrm{H},{ }^{13} \mathrm{C}$ HSQC, gHMBC (optimised for $5 \mathrm{~Hz}$ coupling constant) and HSQC-TOCSY (mixing time $80 \mathrm{~ms}$ ). Spectra were assigned with the help of the computer program PRONTO. ${ }^{25}$

2.5.2. Mass spectrometry. Ion cyclotron resonance ESI FTMS was performed in the negative ion mode using an APEX II-Instrument (Bruker Daltonics, USA) equipped with a $7 \mathrm{~T}$ magnet and an Apollo ion source. Mass spectra were acquired using standard experimental sequences as provided by the manufacturer. Samples ( $\left.10 \mathrm{ng} \mu \mathrm{L}^{-1}\right)$, in 50:50:0.001 2-propanol-water- $\mathrm{Et}_{3} \mathrm{~N}$, were sprayed at a flow rate of $2 \mu \mathrm{L} \mathrm{min}{ }^{-1}$. Capillary entrance voltage was set to $3.8 \mathrm{kV}$, and drying gas temperature to $150{ }^{\circ} \mathrm{C}$. The spectra, which showed several charge states for each component, were charge deconvoluted, and mass numbers given refer to the monoisotopic molecular masses. Capillary skimmer dissociation (CSD) was induced by increasing the capillary exit voltage from -100 to $-350 \mathrm{~V}$. Infrared multi-photon dissociation (IRMPD) of isolated parent ions was performed with a $35 \mathrm{~W}, 10.6 \mu \mathrm{m} \mathrm{CO}_{2}$ laser (Synrad, USA). The unfocused laser beam was directed through the centre of the trap. Duration of laser irradiation was adapted to generate optimal fragmentation and varied between 10 and $80 \mathrm{~ms}$. Fragment ions were detected after a delay of $0.5 \mathrm{~ms}$.

\section{Results and discussion}

Reactivity of Proteus OX strains with sera from patients with rickettsial diseases were studied using immunoblot- ting following SDS-PAGE (Fig. 1). Serum from a patient with murine typhus bound to both slow- and fast-migrating bands of the LPSs from two P. vulgaris OX19 strains [ATCC6380 and Jpn; Fig. 1(A), lanes 3 and 4], which correspond to the species with long and short or no O-polysaccharide chain, respectively. In accordance with an earlier observation, ${ }^{5}$ serum from a patient with Japanese spotted fever cross-reacted with slow-migrating (strong) and fast-migrating (weak) bands of the LPSs from two P. vulgaris OX2 strains [PrO8/44 and Jpn; Fig. 1(B), lanes 5 and 6] and fastmigrating bands (weak) of the LPS from $P$. vulgaris OX19 [Fig. 1(B), lanes 3 and 4]. Serum from a patient with scrub typhus reacted only with slow-migrating bands of the LPSs from $P$. mirabilis OXK and $P$. mirabilis S1959 [Fig. 1(C), lanes 2 and 1, respectively],

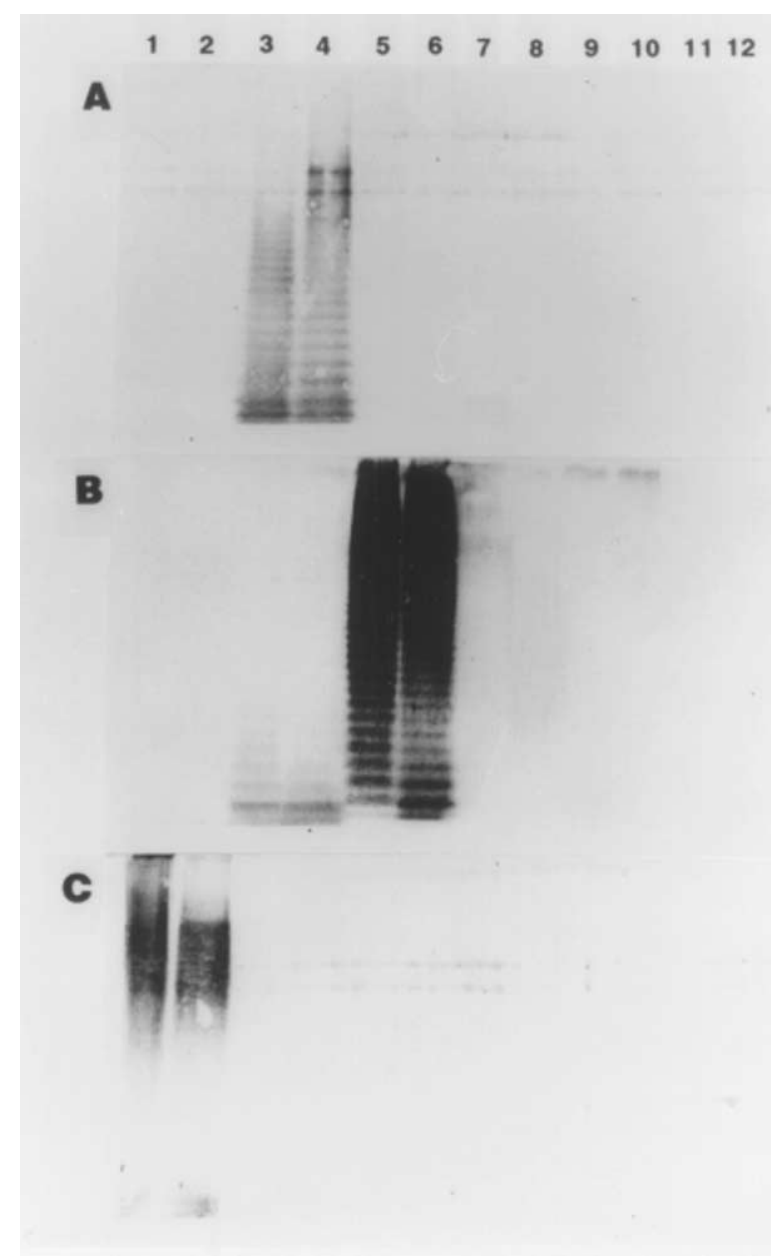

Fig. 1. Antigenic components in the Proteus LPSs detected by immunoblotting with IgM antibodies in sera from patients with murine typhus (A), Japanese spotted fever (B) and scrub typhus (C). Lanes show the following LPSs: 1, P. mirabilis S1959; 2, P. mirabilis OXK (Jpn); 3, P. vulgaris OX19 (ATCC6380); 4, P. vulgaris OX19 (Jpn); 5, P. vulgaris PrO 8/44; 6, P. vulgaris OX2 (Jpn); 7, P. vulgaris O8; 8, P. penneri 107; 9, P. penneri 40; 10, P. penneri $19 ; 11, P$. penneri $11 ; 12, P$. penneri 2. 
which have the structurally identical O-polysaccharide and, correspondingly, both belong to Proteus serogroup O3. ${ }^{12}$ These data show that sera from patients with rickettsial diseases, except for scrub typhus, may recognize epitopes on both O-polysaccharide and core regions of the LPSs from $P$. vulgaris OX19 and OX2. The LPSs from Proteus non-OX strains, like $P$. vulgaris $\mathrm{O} 8$ and five $P$. penneri strains, did not react with any of the sera [Fig. 1(A-C), lanes 7-12].

Studies on the core structure were performed with the LPSs of $P$. vulgaris OX19 and $P$. mirabilis OXK, which has not been studied in this respect previously. For the purpose of comparison, the LPSs of $P$. vulgaris $\mathrm{OX} 2, P$. mirabilis S1959 and its R-mutant R110 with the full core, which have been previously analysed, ${ }^{13,14}$ were reinvestigated in this work. As in the other Proteus strains studied, ${ }^{11}$ the LPS core of these strains possesses a common fragment in the inner region with four positions, which can be independently substituted with various saccharides and ethanolamine phosphate $\left(\mathrm{R}^{1}\right.$ $\mathrm{R}^{4}$, Fig. 2). From them, $\mathrm{R}^{1}$ (outer core region) is highly variable showing $>20$ structural variants, whereas each of $\mathrm{R}^{2}-\mathrm{R}^{4}$ is represented by a few variants building

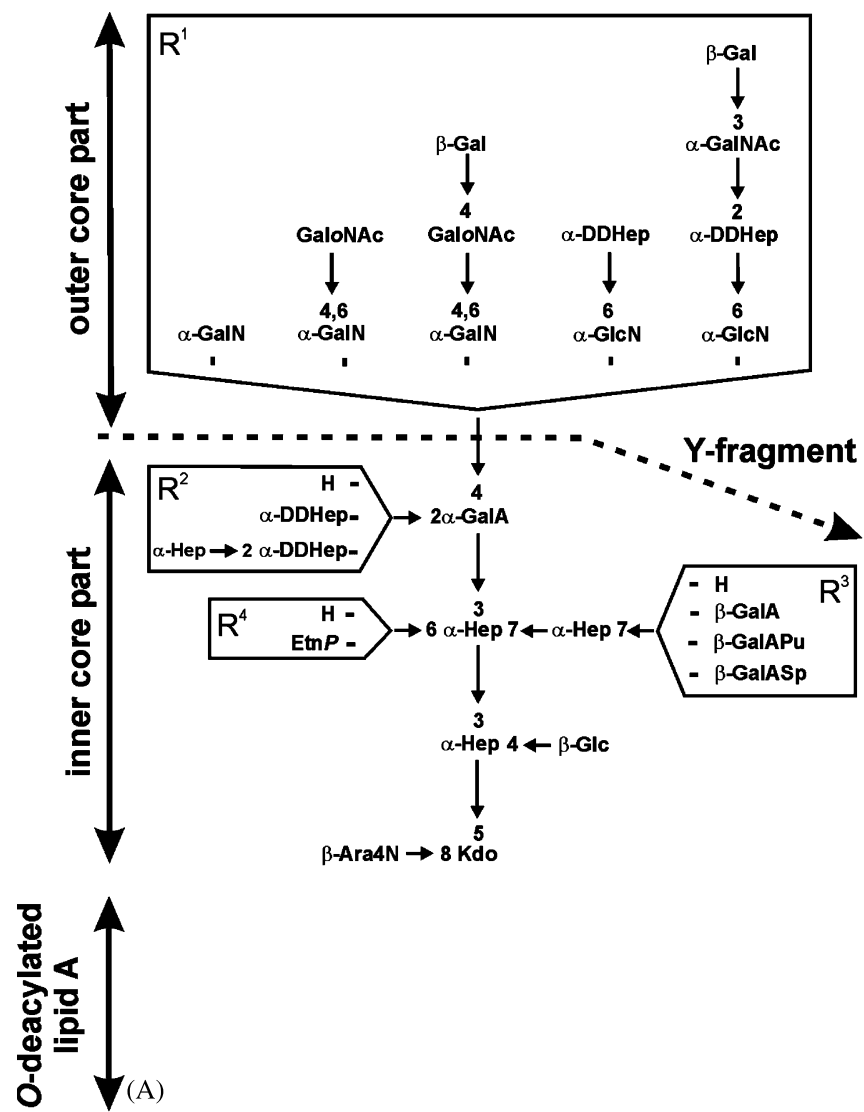

together with the common fragment a more conserved inner core region. ${ }^{11}$ Heterogeneity of lipid A for the Proteus LPS is associated with a varying degree of substitution with fatty acids and the presence or absence of phosphate groups and phosphate-linked Ara4N residues ${ }^{11}\left(\mathrm{R}^{5}\right.$ and $\mathrm{R}^{6}$; Fig. 2(B)).

The LPS samples were delipidated by mild acid hydrolysis to give mixtures of core oligosaccharides $\mathbf{1}$ (Fig. 3), which were isolated by GPC followed by anionexchange chromatography as individual compounds (from $P$. mirabilis OXK) or mixtures of compounds (from the other strains). The oligosaccharides from $P$. vulgaris OX19 were further fractionated by cationexchange chromatography to give four fractions I-IV. Alternatively, the LPS samples were O-deacylated by mild hydrazinolysis, and the resulting products 2 (Fig. 3) were studied without further purification.

The core oligosaccharides 1 were mass analysed in the negative ion mode by ESI FTMS, and examples of the charge deconvoluted spectra of those from $P$. vulgaris OX19 (Fractions I, II and IV), P. mirabilis S1959 and OXK are shown in Fig. 4. The measured mass numbers were in excellent agreement with the calculated mole-

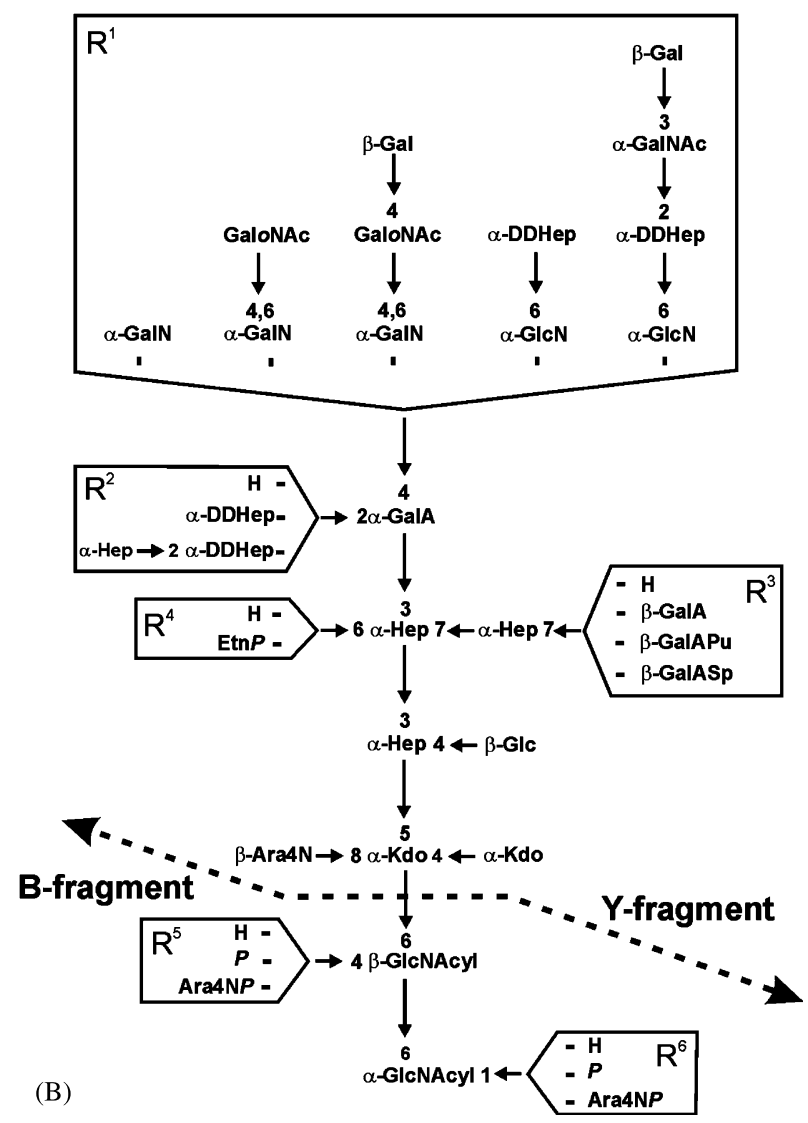

Fig. 2. General structures of the core oligosaccharides (A) and O-deacylated LPSs (B) obtained from the LPSs of Proteus OX by mild acid hydrolysis and mild hydrazinolysis, respectively, and explanation of the mass spectrometric Y-fragments from the reducing end and the B-fragment from the non-reducing end. The variability of the $\mathrm{R}^{1}$ substituent is exemplified with the saccharides that are present in Proteus OX strains. For abbreviations see legend to Fig. 3. 


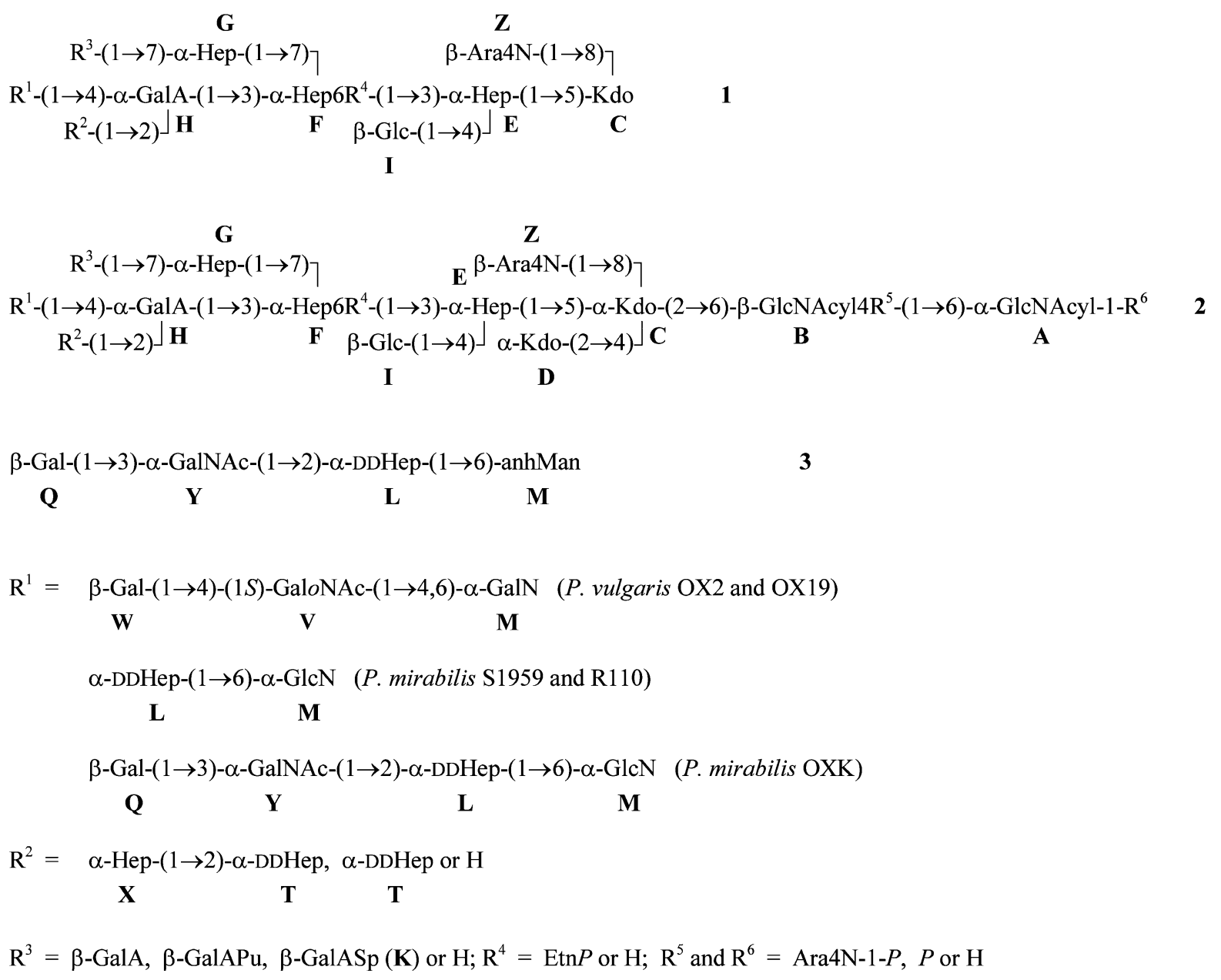

Fig. 3. Structures of the products obtained from the LPSs of Proteus OX by mild acid hydrolysis (1), mild hydrazinolysis (2), and deamination with nitrous acid (3). Acyl stands for $(R)$-3-hydroxytetradecanoyl, Etn $P$ for ethanolamine phosphate, anhMan for 2,5anhydromannose, Hep and DDHep for L- and D-glycero-D-manno-heptose, Kdo for 3-deoxy-D-manno-oct-2-ulosonic acid, Galo NAc for an open chain form of GalNAc, GalAPu and GalASp for amide of GalA with putrescine or spermidine, respectively. For the structural variants, see Tables 1 and 2. In P. vulgaris OX2 and OX19 and P. mirabilis OXK, the oligosaccharide substituent $\mathrm{R}^{1}$ may occur in a truncated form.

cular masses of the core oligosaccharides 1a, 1a' (both from $P$. vulgaris $\mathrm{OX} 2$ ), $\mathbf{1 f}$ and $\mathbf{1 g}$ (both from $P$. mirabilis S1959), whose structures have been already established $^{13,14}$ (Table 1). Compounds $\mathbf{1 a}$ and $\mathbf{1} \mathbf{a}^{\prime}$, together with $\mathbf{1 a}^{\prime \prime}$ having a further truncated oligosaccharide substituent $\mathrm{R}^{1}$, occurred also in Fraction I from $P$. vulgaris OX19 (Fig. 4(A)), whereas Fractions II-IV (Fig. 4(B, C)) contained other oligosaccharides (1b-1e). Based on their molecular masses, it was concluded that 1b-1e have an additional substituent $\mathrm{R}^{3}=$ amide of GalA $\mathbf{K}$ with polyamines putrescine or spermidine (GalAPu and GalASp), which has been identified earlier in the LPSs of a number of other Proteus strains. ${ }^{11}$ This conclusion was confirmed by the behaviour of $\mathbf{1 b}-\mathbf{1 e}$ in cation-exchange chromatography and by MS/MS data (see below). Remarkably, as in some other Proteus strains, ${ }^{11}$ in $\mathbf{1 b}-\mathbf{1 e}$ either substituent $\mathrm{R}^{2}=$ Hep-DDHep $(\mathbf{X}-\mathbf{T})$ or $\mathrm{R}^{4}=\operatorname{Etn} P$, but not both, is absent (Table 1), thus showing a mutual dependence of the action of enzymes involved in the stepwise assembly of the core oligosaccharide. Comparison of the data of the nonfractionated 1 from $P$. vulgaris OX19 and those of the isolated fractions indicated that the species with $\mathrm{R}^{3}=$ GalAPu or GalASp are largely discriminated in the spectra of the total mixture, but gave abundant ions in the spectra of Fractions II-IV, from which the species with $\mathrm{R}^{3}=\mathrm{H}$ are absent.

Since different variable saccharide substituents of the core may include the same monosaccharide residues, like heptose $\mathbf{L}$ and $\mathbf{T}$ in $\mathrm{R}^{1}$ and $\mathrm{R}^{2}$, respectively, the structures of the unknown compounds could not be unequivocally inferred from the accurate measurement of their molecular masses. Therefore, MS/MS was applied to solve this problem. The doubly charged negative molecular ions were selected as parent ions and dissociated by infrared multi-photon absorption. 


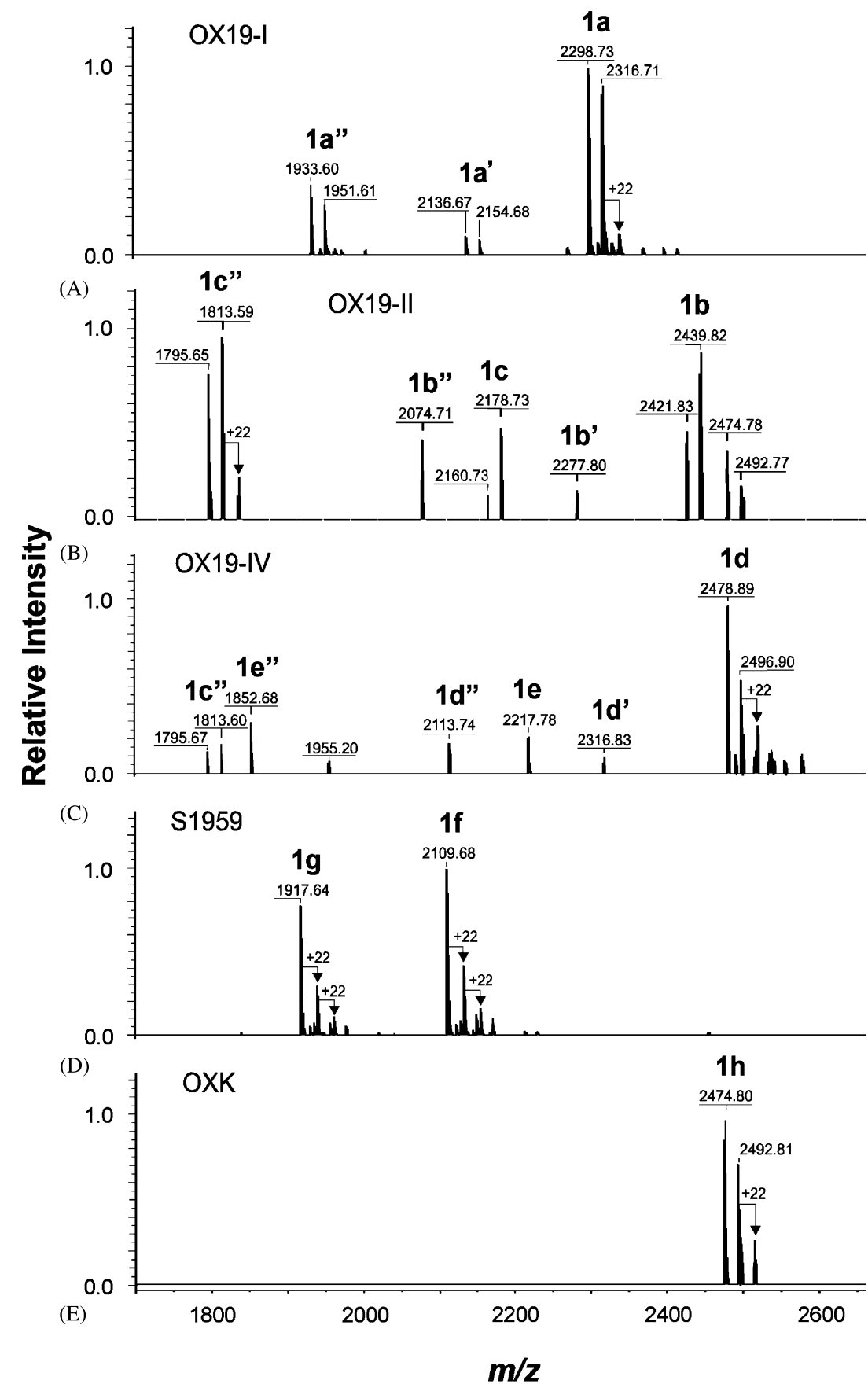

Fig. 4. Charge deconvoluted negative ion ESI FT-MS of the core oligosaccharides 1 from P. vulgaris OX19 (Fractions I, II and IV, A-C), P. mirabilis S1959 (D) and OXK (E) obtained by mild acid hydrolysis of the LPSs. Most mass peaks are accompanied by + 22 and $-18 \mathrm{Da}$ satellite peaks originating from sodium adduct formation and from the corresponding compounds with Kdo in an anhydro form, respectively. For explanation of the mass peaks see Table 1.

The IRMPD-MS/MS spectra of 1 exhibited a few doubly charged fragment ions (Fig. 5). By analysing those compounds whose structures have been elucidated earlier, including the oligosaccharides $\mathbf{1}$ from $P$. vulgaris OX2 and P. mirabilis S1959 (Fig. 5(A, E, F)), the fragmentation pathway could be identified. Some fragments were obtained by decarboxylation of Kdo or anhydro-Kdo accompanied by the loss of two or one water molecules ( -80 or $-62 \mathrm{Da}$, respectively), and the Y-fragment resulted from the rupture of the glycosidic linkage between GalN (GlcN) $\mathbf{M}$ and GalA $\mathbf{H}$, which connects the highly variable outer region of the core $\left(\mathrm{R}^{1}\right)$ and the more conserved inner region (Fig. 2(A)). This fragmentation is of diagnostic importance since it provides information on the composition of all variable saccharide substituents, including $R^{2}$ and $R^{3}$ by 
Table 1

ESI FT-MS data of the core oligosaccharides 1 isolated by mild acid hydrolysis of the Proteus LPSs (monoisotopic molecular mass, Da)

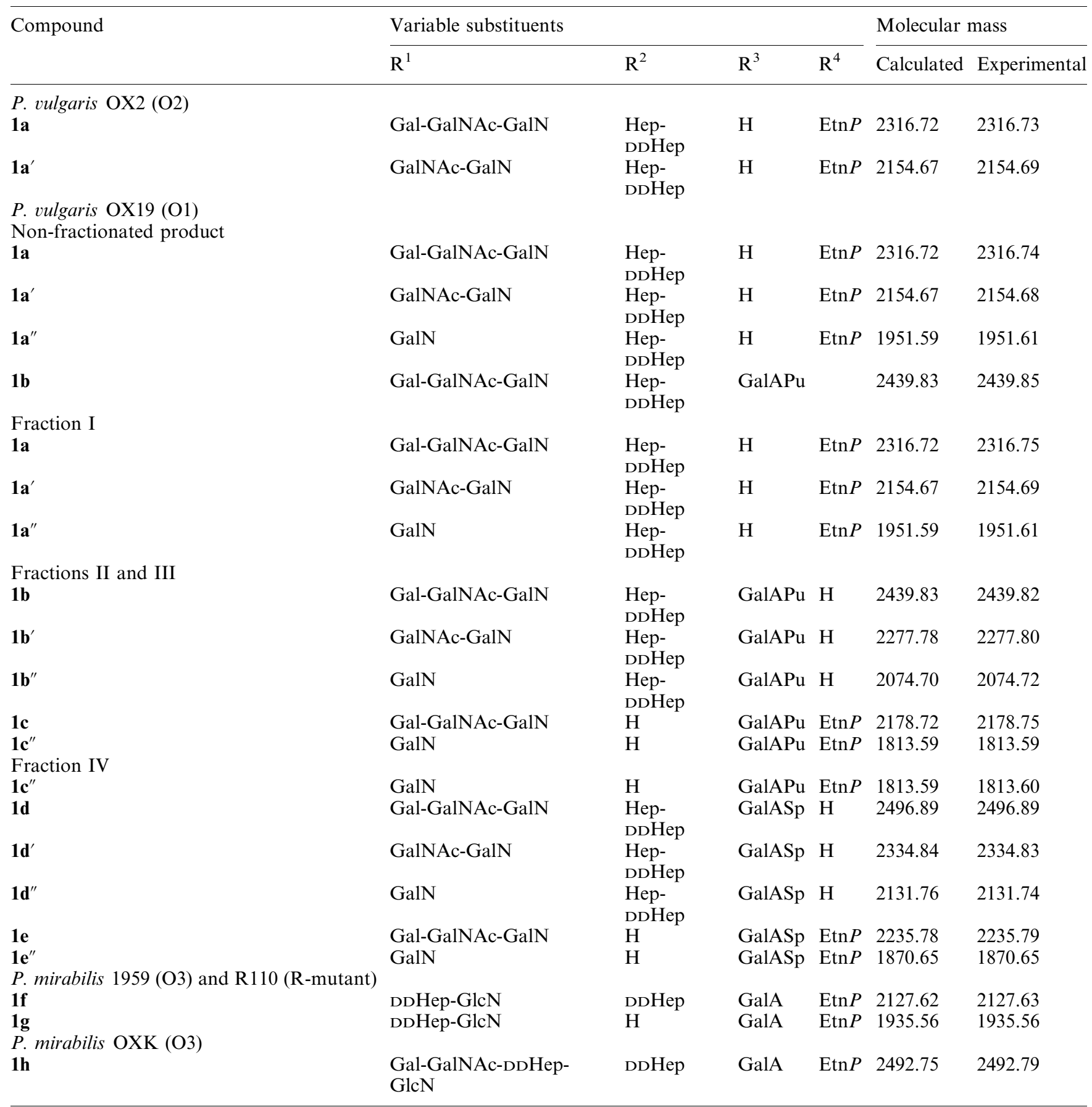

For structure of 1 and abbreviations, see Figs. 2 and 3. Primed numbers refer to the compounds from P. vulgaris OX2 and OX19 with a truncated substituent $\mathrm{R}^{1}$. Mass spectra of some products from $P$. vulgaris $\mathrm{OX} 19$ showed a few minor peaks, which were not assigned.

the exact mass of the $\mathrm{Y}$-fragment and $\mathrm{R}^{1}$ by the mass difference between the parent compound and the $\mathrm{Y}$ fragment. The data obtained confirmed the suggested structures of $\mathbf{1 a}-\mathbf{1 e}$ from the LPS of P. vulgaris OX19 (Table 1, Fig. 3), including the identity of the outer core region to that of $P$. vulgaris $\mathrm{OX} 2 .{ }^{13}$ They also showed 

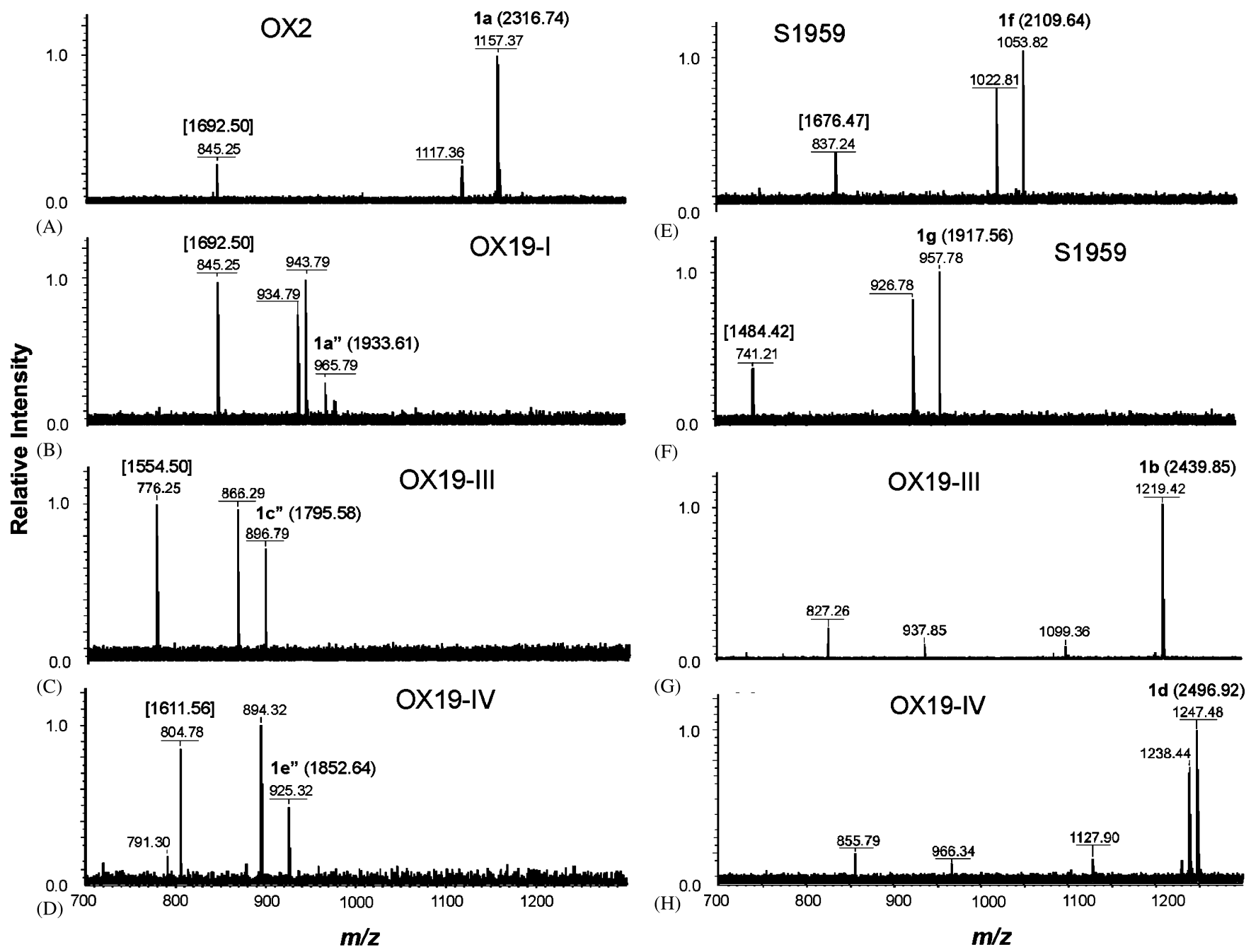

Fig. 5. Negative ion IRMPD-MS/MS spectra of the core oligosaccharides 1 from $P$. vulgaris OX2 (A) OX19 (fractions I, II and IV, B-D, G, H), P. mirabilis S1959 (E) and OXK (F). The molecular mass of the parent compound is indicated in parentheses and that of the Y-fragment in brackets.

that the core of $P$. mirabilis OXK (1h) has the same inner region as that of $P$. mirabilis $\mathrm{S} 1959$ but a different outer region $\left(\mathrm{R}^{1}\right)$, which is represented by a HexHexNHexNAcHep tetrasaccharide rather than a HexNHep disaccharide present in P. mirabilis S1959 (Table 1, Fig. 3).

When the ethanolamine phosphate group is absent from position 6 of heptose $\mathbf{F}\left(\mathrm{R}^{4}=\mathrm{H}\right)$, as in oligosaccharides $\mathbf{1 b}$ and $\mathbf{1 d}$ from $P$. vulgaris OX19 (Table 1) and some other Proteus strains, ${ }^{11}$ a different, yet unknown fragmentation was observed in IRMPD-MS/MS (Fig. $5(\mathrm{G}, \mathrm{H}))$. It resulted in fragments that contain at least one of the variable substituents, namely $\mathrm{R}^{3}$, as followed from the correspondingly different masses of the ions that were derived from oligosaccharides $\mathbf{1 b}\left(\mathrm{R}^{3}=\right.$ GalAPu) and 1d $\left(\mathrm{R}^{3}=\right.$ GalASp). Hence, Etn $P$ influences the stability of the linkage between GalN (GlcN) $\mathbf{M}$ and GalA $\mathbf{H}$ and its presence is necessary for the formation of the Y-fragment. However, in Proteus most structural variants of the LPS, and in many Proteus strains all variants, do contain $\operatorname{Etn} P$, and therefore, the IRMPD-MS/MS approach will be useful in structural analysis of the LPS cores in Proteus strains that have not been studied yet in this respect. Particularly, it will enable screening of the core oligosaccharides to assign the structures of the relatively conserved inner core region and, in combination with serological testing, to select for further studies strains with outer core regions that have not been yet identified in Proteus LPSs. ${ }^{11}$

The results of ESI FTMS analysis of the O-deacylated LPS 2 are summarized in Table 2, and examples of the charge deconvoluted spectra of $\mathbf{2}$ from $P$. vulgaris $\mathrm{OX} 2$ and $P$. mirabilis OXK are shown in Fig. 6. As expected, O-deacylated LPSs 2 showed more complex mass spectra owing to additional heterogeneity because of different substituents in lipid $A\left(R^{5}\right.$ and $\left.R^{6}\right)$, each of which, when present, is either phosphate or Ara4N-1-P (Fig. 2). In addition to the major products $\mathbf{2 h}$, two minor 
Table 2

ESI FT-MS data of the O-deacylated Proteus LPSs 2 (monoisotopic molecular mass, Da)

\begin{tabular}{|c|c|c|c|c|c|c|c|}
\hline \multirow[t]{2}{*}{ Compound } & \multicolumn{5}{|l|}{ Variable substituents } & \multicolumn{2}{|c|}{ Molecular mass } \\
\hline & $\mathrm{R}^{1}$ & $\mathrm{R}^{2}$ & $\mathrm{R}^{3}$ & $\mathrm{R}^{4}$ & $\mathrm{R}^{5}, \mathrm{R}^{6}$ & Calculated & Experimental \\
\hline \multicolumn{8}{|l|}{ P. vulgaris $\mathrm{OX} 2(\mathrm{O} 2)$} \\
\hline \multirow[t]{4}{*}{$2 a$} & Gal-GalNAc-GalN & $\begin{array}{l}\text { Hep- } \\
\text { DDHep }\end{array}$ & $\mathrm{H}$ & $\operatorname{Etn} P$ & $\begin{array}{l}\text { Ara4N } P \\
\text { Ara4N } P\end{array}$ & 3733.36 & 3733.36 \\
\hline & Gal-GalNAc-GalN & $\begin{array}{l}\text { Hep- } \\
\text { DDHep }\end{array}$ & $\mathrm{H}$ & $\operatorname{Etn} P$ & Ara4N $P, P$ & 3602.30 & 3602.29 \\
\hline & Gal-GalNAc-GalN & $\begin{array}{l}\text { Hep- } \\
\text { DDHep }\end{array}$ & $\mathrm{H}$ & $\operatorname{Etn} P$ & $\operatorname{Ara} 4 \mathrm{~N} P, \mathrm{H}$ & 3522.33 & 3522.38 \\
\hline & Gal-GalNAc-GalN & $\begin{array}{l}\text { Hep- } \\
\text { DDHep }\end{array}$ & $\mathrm{H}$ & $\operatorname{Etn} P$ & $P, \mathrm{H}$ & 3391.27 & 3391.27 \\
\hline \multirow[t]{2}{*}{$2 a^{\prime}$} & GalNAc-GalN & $\begin{array}{l}\text { Hep- } \\
\text { DDHep }\end{array}$ & $\mathrm{H}$ & $\operatorname{Etn} P$ & Ara4N $P, P$ & 3440.25 & 3440.28 \\
\hline & GalNAc-GalN & $\begin{array}{l}\text { Hep- } \\
\text { DDHep }\end{array}$ & $\mathrm{H}$ & $\operatorname{Etn} P$ & $P, \mathrm{H}$ & 3229.22 & 3229.20 \\
\hline \multirow{5}{*}{$\begin{array}{l}\text { P. vulgaris } \mathrm{OX} 19(\mathrm{O} 1) \\
\text { 2a }\end{array}$} & & & & & & & \\
\hline & Gal-GalNAc-GalN & $\begin{array}{l}\text { Hep- } \\
\text { DDHep }\end{array}$ & $\mathrm{H}$ & $\operatorname{Etn} P$ & $\begin{array}{l}\text { Ara4N } P \\
\text { Ara } 4 \text { N } P\end{array}$ & 3733.36 & 3733.36 \\
\hline & Gal-GalNAc-GalN & $\begin{array}{l}\text { Hep- } \\
\text { DDHep }\end{array}$ & $\mathrm{H}$ & $\operatorname{Etn} P$ & Ara4N $P, P$ & 3602.30 & 3602.32 \\
\hline & Gal-GalNAc-GalN & $\begin{array}{l}\text { Hep- } \\
\text { DDHep }\end{array}$ & $\mathrm{H}$ & $\operatorname{Etn} P$ & Ara4N $P, \mathrm{H}$ & 3522.33 & 3522.35 \\
\hline & Gal-GalNAc-GalN & $\begin{array}{l}\text { Hep- } \\
\text { DDHep }\end{array}$ & $\mathrm{H}$ & $\operatorname{Etn} P$ & $P, \mathrm{H}$ & 3391.27 & 3391.30 \\
\hline \multirow[t]{3}{*}{$2 a^{\prime \prime}$} & GalN & $\begin{array}{l}\text { Hep- } \\
\text { DDHep }\end{array}$ & $\mathrm{H}$ & $\operatorname{Etn} P$ & $\begin{array}{l}\text { Ara4N } P \\
\text { Ara4N } P\end{array}$ & 3368.23 & 3368.23 \\
\hline & GalN & $\begin{array}{l}\text { Hep- } \\
\text { DDHep }\end{array}$ & $\mathrm{H}$ & $\operatorname{Etn} P$ & Ara4N $P, P$ & 3237.17 & 3237.17 \\
\hline & GalN & $\begin{array}{l}\text { Hep- } \\
\text { DDHep }\end{array}$ & $\mathrm{H}$ & $\operatorname{Etn} P$ & $\operatorname{Ara} 4 \mathrm{~N} P, \mathrm{H}$ & 3157.20 & 3157.23 \\
\hline $2 \mathbf{b}$ & Gal-GalNAc-GalN & $\begin{array}{l}\text { Hep- } \\
\text { DDHep }\end{array}$ & GalAPu & $\mathrm{H}$ & $\begin{array}{l}\text { Ara4N } P \\
\text { Ara4N } P\end{array}$ & 3856.49 & 3856.47 \\
\hline \multicolumn{8}{|l|}{$\begin{array}{l}\text { P. mirabilis S1959 (O3) and R110 (R- } \\
\text { mutant) }\end{array}$} \\
\hline \multirow[t]{3}{*}{$2 f$} & DoHep-GlcN & DoHep & GalA & $\operatorname{Etn} P$ & $\begin{array}{l}\text { Ara4N } P \\
\text { Ara } 4 \mathrm{~N} P\end{array}$ & 3544.26 & 3544.25 \\
\hline & DDHep-GlcN & DoHep & GalA & $\operatorname{Etn} P$ & Ara4N $P, P$ & 3413.20 & 3413.21 \\
\hline & DoHep-GlcN & DoHep & GalA & $\operatorname{Etn} P$ & $P, P$ & 3282.14 & 3282.17 \\
\hline \multirow[t]{3}{*}{$2 \mathrm{~g}$} & DoHep-GlcN & $\mathrm{H}$ & GalA & $\operatorname{Etn} P$ & $\begin{array}{l}\text { Ara } 4 \mathrm{~N} P \\
\text { Ara } 4 \mathrm{~N} P\end{array}$ & 3352.20 & 3352.25 \\
\hline & DDHep-GlcN & $\mathrm{H}$ & GalA & $\operatorname{Etn} P$ & Ara4N $P, P$ & 3221.14 & 3221.15 \\
\hline & DDHep-GlcN & $\mathrm{H}$ & GalA & $\operatorname{Etn} P$ & $P, P$ & 3090.08 & 3090.11 \\
\hline \multirow{5}{*}{$\begin{array}{l}\text { P. mirabilis } \mathrm{OXK}(\mathrm{O} 3) \\
\mathbf{2 h}\end{array}$} & & & & & & & \\
\hline & $\begin{array}{l}\text { Gal-GalNAc-DDHep- } \\
\text { GlcN }\end{array}$ & DDHep & GalA & $\operatorname{Etn} P$ & $\begin{array}{l}\text { Ara4N } P \\
\text { Ara4N } P\end{array}$ & 3909.38 & 3909.38 \\
\hline & $\begin{array}{l}\text { Gal-GalNAc-DDHep- } \\
\text { GlcN }\end{array}$ & DDHep & GalA & $\operatorname{Etn} P$ & Ara4N $P, P$ & 3778.33 & 3778.33 \\
\hline & $\begin{array}{l}\text { Gal-GalNAc-DDHep- } \\
\text { GlcN }\end{array}$ & DDHep & GalA & $\operatorname{Etn} P$ & $P, P$ & 3647.25 & 3647.25 \\
\hline & $\begin{array}{l}\text { Gal-GalNAc-DDHep- } \\
\text { GlcN }\end{array}$ & DDHep & GalA & $\operatorname{Etn} P$ & $P, \mathrm{H}$ & 3567.28 & 3567.33 \\
\hline \multirow[t]{2}{*}{$2 \mathbf{i}$} & $\begin{array}{l}\text { Gal-GalNAc-DDHep- } \\
\text { GlcN }\end{array}$ & DoHep & $\mathrm{GalAPu}$ & $\operatorname{Etn} P$ & Ara4N $P, P$ & 3848.43 & 3848.43 \\
\hline & $\begin{array}{l}\text { Gal-GalNAc-DDHep- } \\
\text { GlcN }\end{array}$ & DoHep & GalAPu & $\operatorname{Etn} P$ & $P, P$ & 3717.35 & 3717.37 \\
\hline $2 \mathrm{j}$ & $\begin{array}{l}\text { Gal-GalNAc-DDHep- } \\
\text { GlcN }\end{array}$ & $\mathrm{H}$ & GalA & $\operatorname{Etn} P$ & Ara4N $P, P$ & 3586.27 & 3586.29 \\
\hline
\end{tabular}

For structure of 2 and abbreviations see Fig. 2 and Table 3. Primed numbers refer to the compounds from P. vulgaris OX2 and OX19 with a truncated substituent $\mathrm{R}^{1}$. Mass spectra of some products from $P$. vulgaris $\mathrm{OX} 19$ showed a few additional minor peaks, which were not assigned. 


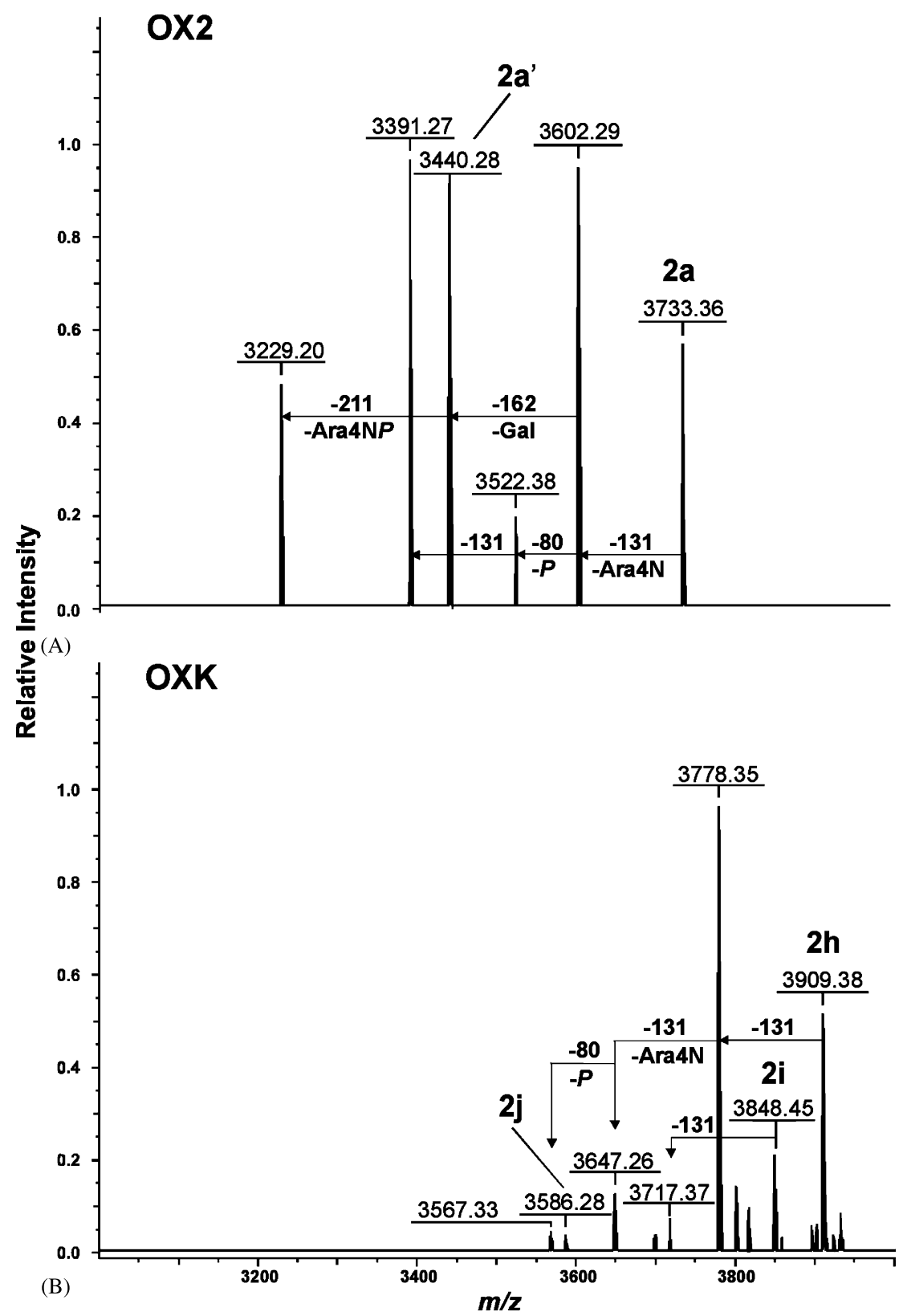

Fig. 6. Charge deconvoluted negative ion ESI FT-mass spectra of the O-deacylated LPSs 2 from P. vulgaris OX2 (A) and P. mirabilis OXK (B). Sodium adduct ions (+22 Da) are observed for some peaks. For explanation of the mass peaks see Table 2.

products were derived from the LPS of $P$. mirabilis OXK, which have the same substituent $\mathrm{R}^{1}$ but differ from $\mathbf{2 h}$ in amidation of GalA $\mathbf{K}\left(\mathrm{R}^{3}\right)$ with putrescine (2i) or in the absence of the substituent $R^{2}(\mathbf{2} \mathbf{j})$. No corresponding minor core oligosaccharides $\mathbf{1 i}$ and $\mathbf{1 j}$ were detected after mild acid hydrolysis of the LPS.

Additional structural information could be obtained by CSD (Fig. 7), which induced a fragmentation in $\mathbf{2}$ due to the rupture of the linkage between GlcN B of lipid A and $\mathrm{Kdo} \mathbf{C}$ of the inner core region to give the respective Y- and B-fragments (Fig. 2(B)). Since two amide-linked 3-hydroxymyristic acid residues are present in all molecular species, the nature of the substituents $R^{5}$ and $\mathrm{R}^{6}$ in $\mathbf{2}$ can be determined directly from the analysis of the Y-fragment. Although cleavage of phosphate and Ara4N can occur to some extent, the CSD spectra show significant difference in the substitution pattern of lipid A. For instance, the mass region of the Y-fragments from the O-deacylated LPSs demonstrated that the content of Ara4N in lipid A of $P$. vulgaris OX2 (Fig. $7(\mathrm{~A})$ ) is considerably higher than that in $P$. mirabilis OXK (Fig. 7(B)). In contrast, the degree of phosphorylation of lipid A is much higher in P. mirabilis OXK. The analysis of the B-fragments confirmed that, in addition to Kdo $\mathbf{C}$, the LPS core contains the second $\mathrm{Kdo}$ residue $\mathbf{D}$ in all strains. 


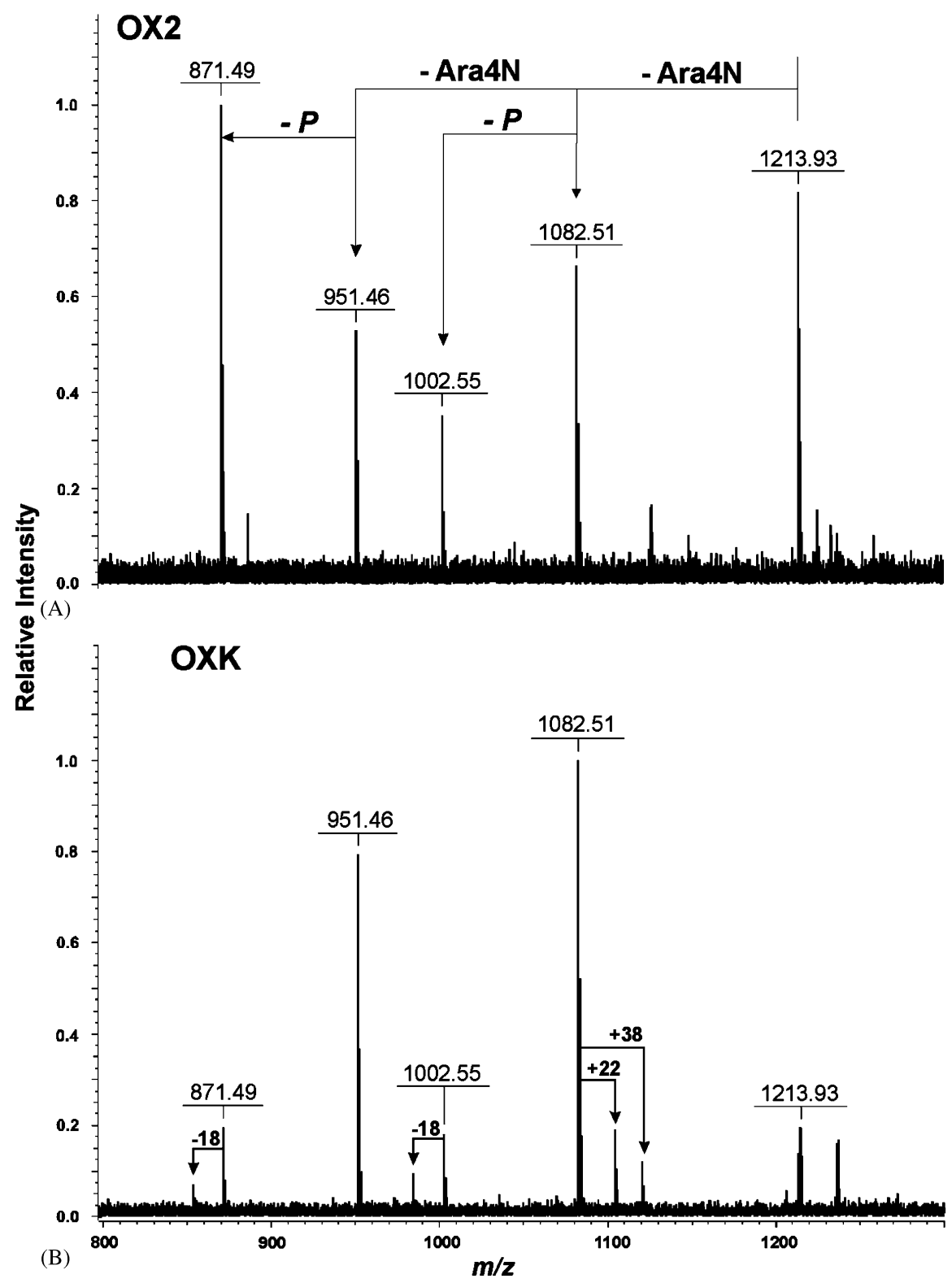

Fig. 7. The region of the Y-fragments in the CSD mass spectra of the O-deacylated LPSs 2 from $P$. vulgaris OX2 (A) and $P$. mirabilis OXK (B). The Y-fragment ion peak at $\mathrm{m} / \mathrm{z} 1213.93$ corresponds to the tetraacyl lipid A species with two Ara4N $P$ groups.

The data obtained for the products $\mathbf{1}$ and $\mathbf{2}$ derived from the LPSs of $P$. vulgaris $\mathrm{OX} 2$ and $P$. mirabilis S1959 were essentially consistent with the core structures established earlier ${ }^{13,14}$ (Fig. 3, Tables 1 and 2). Particularly, they confirmed an incomplete substitution with Gal $\mathbf{W}$ in P. vulgaris OX2 (core variants $\mathbf{1 a}$ and $\mathbf{1} \mathbf{a}^{\prime}$ ) and with Hep $\mathbf{X}$ in $P$. mirabilis S1959 (core variants 1 ff and 1g). However, no confirmation was obtained for incomplete substitution with Ara4N Z, which was suggested earlier by studies of the strong alkaline deacylation products of the LPSs of both strains. ${ }^{13,14}$ This can be accounted for by partial elimination of Ara4N $\mathbf{Z}$ during strong alkaline degradation of the LPSs in the previous studies, ${ }^{13,14}$ and thus the resulting Ara4N-lacking compounds were artefacts.
The MS data suggested that the LPS of P. vulgaris OX19 has the same outer core region $\left(\mathrm{R}^{1}\right)$ as that of $P$. vulgaris $\mathrm{OX} 2$, which in its full form represents a trisaccharide containing a GalNAc residue in an openchain form. ${ }^{11}$ This finding was confirmed by comparative NMR spectroscopic studies of core oligosaccharides 1 from both strains (data not shown). They also share some inner core variants $\left(\mathbf{a}-\mathbf{a}^{\prime \prime}\right)$, whereas the LPS of $P$. vulgaris OX19 includes a number of other variants with an additional substituent $\mathrm{R}^{3}=\mathrm{GalAPu}$ and GalASp (be and the corresponding $\mathrm{R}^{1}$-truncated forms; Table 1 ).

The major core variant $\mathbf{h}$ in $P$. mirabilis $\mathrm{OXK}$ has the same inner core region with the same substituents $\mathrm{R}^{2}$ $\mathrm{R}^{4}$ as the core variant $\mathbf{f}$ in $P$. mirabilis $\mathrm{S} 1959$ and $\mathrm{R} 110$ but possesses a different outer core region $\mathrm{R}^{1}$. In $P$. 
Table 3

${ }^{1} \mathrm{H}$ and ${ }^{13} \mathrm{C}$ NMR data of the oligosaccharide $\mathbf{1 h}$ and tetrasaccharide $\mathbf{3}$ from the LPS of $P$. mirabilis OXK

\begin{tabular}{|c|c|c|c|c|c|c|c|c|c|c|c|}
\hline \multirow[t]{2}{*}{ Sugar residue } & \multirow[t]{2}{*}{ Nucleus } & \multicolumn{8}{|c|}{ Chemical shift $(\delta, \mathrm{ppm})$} & \multicolumn{2}{|c|}{ Correlation for $\mathrm{H}-1$} \\
\hline & & 1 & 2 & 3 & 4 & 5 & $6(6 a)$ & $7 a(6 b)$ & $7 b$ & NOESY & НМBC \\
\hline \multicolumn{12}{|l|}{ Oligosaccharide $\mathbf{1 h}$} \\
\hline \multirow[t]{2}{*}{$\alpha-\mathrm{GalA} \mathbf{H}$} & ${ }^{1} \mathrm{H}$ & 5.60 & 4.08 & 4.19 & 4.41 & 4.44 & & & & F H-3 & F C-3 \\
\hline & ${ }^{13} \mathrm{C}$ & 98.3 & 72.2 & 67.9 & 80.7 & 72.3 & & & & & \\
\hline \multirow[t]{2}{*}{$\alpha-G l c N ~ M$} & ${ }^{1} \mathrm{H}$ & 5.14 & 3.24 & 3.84 & 3.59 & 4.42 & 3.60 & 4.04 & & H H-4,5 & H C-4 \\
\hline & ${ }^{13} \mathrm{C}$ & 97.8 & 55.3 & 71.7 & 70.4 & 72.0 & 66.0 & & & & \\
\hline \multirow[t]{2}{*}{$\alpha$-DDHep $\mathbf{L}$} & ${ }^{1} \mathrm{H}$ & 5.16 & 3.94 & 3.93 & 3.85 & 3.71 & 4.03 & & & M H-6a,6b & M C-6 \\
\hline & ${ }^{13} \mathrm{C}$ & 99.0 & 80.4 & 71.6 & 68.5 & 74.0 & 73.0 & & & Y H-5 & \\
\hline \multirow[t]{2}{*}{$\alpha$-GalNAc Y } & ${ }^{1} \mathrm{H}$ & 5.08 & 4.32 & 4.03 & 4.25 & 4.08 & 3.73 & 3.75 & & L $\mathrm{H}-1,2$ & L C-2 \\
\hline & ${ }^{13} \mathrm{C}$ & 100.9 & 50.2 & 78.1 & 69.8 & 72.2 & 62.2 & & & & \\
\hline \multirow[t]{2}{*}{$\beta$-Gal Q } & ${ }^{1} \mathrm{H}$ & 4.50 & 3.52 & 3.62 & 3.91 & 3.67 & 3.73 & 3.73 & & Y H-3 & Y C-3 \\
\hline & ${ }^{13} \mathrm{C}$ & 105.7 & 71.8 & 73.5 & 69.7 & 76.1 & 62.2 & & & & \\
\hline \multirow[t]{2}{*}{$\alpha$-DDHep $\mathbf{T}$} & ${ }^{1} \mathrm{H}$ & 5.12 & 3.96 & 3.81 & 3.74 & 3.88 & 3.98 & & & H H-1,2 & H C-2 \\
\hline & ${ }^{13} \mathrm{C}$ & 97.9 & 71.0 & 71.6 & 68.1 & 74.5 & 72.5 & & & & \\
\hline \multirow[t]{2}{*}{$\beta$-GalA K } & ${ }^{1} \mathrm{H}$ & 4.42 & 3.56 & 3.71 & 4.20 & 4.04 & & & & G H-7 & G C-7 \\
\hline & ${ }^{13} \mathrm{C}$ & 103.6 & 71.8 & 73.9 & 71.4 & 76.7 & & & & & \\
\hline \multicolumn{12}{|l|}{ Tetrasaccharide $\mathbf{3}$} \\
\hline \multirow[t]{2}{*}{ anhMan M } & ${ }^{1} \mathrm{H}$ & 5.06 & 3.73 & 4.17 & 4.10 & 4.02 & 3.66 & 3.83 & & & \\
\hline & ${ }^{13} \mathrm{C}$ & 90.7 & 85.4 & 78.4 & 77.7 & 82.2 & 67.5 & & & & \\
\hline \multirow[t]{2}{*}{$\alpha$-DDHep $\mathbf{L}$} & ${ }^{1} \mathrm{H}$ & 5.19 & 3.93 & 3.96 & 3.84 & 3.72 & 4.04 & 3.70 & 3.83 & M H-6a,6b & M C-6 \\
\hline & ${ }^{13} \mathrm{C}$ & 99.2 & 80.7 & 71.5 & 68.4 & 74.2 & 72.8 & 62.8 & & Y $\mathrm{H}-5$ & \\
\hline \multirow[t]{2}{*}{$\alpha$-GalNAc Y } & ${ }^{1} \mathrm{H}$ & 5.06 & 4.32 & 4.01 & 4.24 & 4.08 & 3.72 & 3.75 & & L H-1,2 & L C-2 \\
\hline & ${ }^{13} \mathrm{C}$ & 101.1 & 50.1 & 78.0 & 69.7 & 72.3 & 62.2 & & & & \\
\hline \multirow{2}{*}{$\beta-G a l \mathbf{Q}$} & ${ }^{1} \mathrm{H}$ & 4.49 & 3.51 & 3.90 & 3.66 & 3.74 & 3.77 & & & Y H-3 & Y C-3 \\
\hline & ${ }^{13} \mathrm{C}$ & 105.7 & 71.8 & 73.6 & 69.7 & 76.0 & 62.1 & & & & \\
\hline
\end{tabular}

mirabilis $\mathrm{OXK}$, the substituent $\mathrm{R}^{1}$ is a tetrasaccharide, which, most likely, contains the same DDHep-GlcN disaccharide $(\mathbf{L}-\mathbf{M})$ as $P$. mirabilis $\mathrm{S} 1959^{14}$ and, in addition, one hexose and one $N$-acetylhexosamine residue (the total mass difference $\sim 365 \mathrm{Da}$ ). No such structure has been reported previously in any Proteus LPS. ${ }^{11}$

In order to determine the structure of the outer core region, the LPS of $P$. mirabilis OXK was cleaved by deamination at GlcN $\mathbf{M}^{11}$ and the resultant tetrasaccharide 3 with 2,5-anhydromannose (anhMan $\mathbf{M}$ ) at the reducing end was isolated by GPC followed by reversephase HPLC. The core oligosaccharide $\mathbf{1 h}$ and tetrasaccharide 3 were studied by 2D NMR spectroscopy as described ${ }^{26}$ including the assignment of the ${ }^{1} \mathrm{H}$ and ${ }^{13} \mathrm{C}$ NMR spectra by COSY, TOCSY, ${ }^{1} \mathrm{H},{ }^{13} \mathrm{C}$ HSQC and HMQC-TOCSY techniques along with linkage and sequence analyses using NOESY and HMBC experiments (Table 3). The data obtained confirmed the presence of the $\mathbf{L}-\mathbf{M}$ disaccharide, which bears a GalGalNAc disaccharide $(\mathbf{Q}-\mathbf{Y})$ at position 2 of DDHep $\mathbf{L}$. Therefore, the substituent $\mathrm{R}^{1}$ in the LPS core of $P$. mirabilis OXK has the structure shown in Fig. 3.

The presence of the tetrasaccharide outer core region is a peculiar feature of the LPS of P. mirabilis OXK.
This feature is evidently responsible for a serological difference between the LPSs of $P$. mirabilis OXK and S1959, which was observed in passive hemolysis test with absorbed rabbit polyclonal anti- $P$. mirabilis OXK serum. ${ }^{6}$ Indeed, both LPSs have the same O-polysaccharide chain ${ }^{12}$ and the same inner core region (this work), and, hence, rabbit anti- $P$. mirabilis OXK serum contains, inter alia, antibodies that are specific to a GalGalNAc-associated epitope in the outer core region.

To sum up, the general architecture of the LPS core and the structure of the inner core region in Proteus OX strains are typical of those of most other Proteus strains studied. ${ }^{11}$ In the LPSs of P. vulgaris OX2 and OX19 the outer core region has the same structure, which is also shared by a number of other, non-OX Proteus strains. ${ }^{11}$ Therefore, it is unlikely that the core of these LPSs is involved in specific binding to antibodies in sera from patients with rickettsiosis. The outer core region of $P$. mirabilis OXK is unique among Proteus LPSs but, according to the Western blot data (Fig. 1), the LPS core of this strain is not recognised by antibodies in serum from patients with scrub typhus. Moreover, the LPS of $P$. mirabilis S1959, which has the same O-polysaccharide but different outer core regions, reacted with the serum similarly to that of $P$. mirabilis OXK (Fig. 1). 
These data show that the O-polysaccharides of Proteus $\mathrm{OX}$ are exclusively responsible for the cross-reactivity in Weil-Felix test for serodiagnosis of rickettsiosis.

\section{Acknowledgements}

This work was supported by grants 02-04-48767 from the Russian Foundation for Basic Research, YS 2001-2/ 1 from INTAS, and LI-448 from the Deutsche Forschungsgemeinschaft.

\section{References}

1. Vinson, J. W. In Manual of Clinical Immunology; Rose, R.; Frideman, F., Eds.; ASM: Washington, DC, 1976; pp 500-504.

2. Dash, G. A.; Weiss, E. In The Prokaryotes. A Handbook on the Biology of Bacteria: Ecophysiology, Isolation, Identification, Applications; Balows, A.; Trüper, H. G.; Dworkin, M.; Harder, W.; Schleifer, H.-H., Eds.; Springer: Heidelberg, 1991; pp 2407-2470.

3. Raoult, D.; Roux, V. Clin. Microbiol. Rev. 1997, 10, 694714.

4. Amano, K.; Kyohno, K.; Aoki, S.; Suto, T. Microbiol. Immunol. 1995, 39, 63-65.

5. Amano, K.; Cedzynski, M.; Swierzko, A. S.; Kyohno, K.; Kaca, W. Arch. Immunol. Theor. Exp. 1996, 44, 235-240.

6. Kaca, W.; Swierzko, A. S.; Ziolkowski, A.; Amano, K.; Senchenkova, S..; Knirel, Y. A. Microbiol. Immunol. 1998, $42,669-675$.

7. Kaca, W.; Amano, K.; Chernyak, A. Y.; Knirel, Y. A. Microbios 2000, 130, 151-161.

8. Larsson, P. Methods Microbiol. 1984, 14, 187-214.
9. Zych, K.; Kowalczyk, M.; Knirel, Y. A.; Sidorczyk, Z. Adv. Exp. Med. Biol. 2000, 485, 339-344.

10. Knirel, Y. A.; Kaca, W.; Rozalski, A.; Sidorczyk, Z. Pol. J. Chem. 1999, 73, 895-907.

11. Vinogradov, E.; Sidorczyk, Z.; Knirel, Y. A. Aust. J. Chem. 2002, 55, 61-67.

12. Ziolkowski, A.; Shashkov, A. S.; Swierzko, A.; Senchenkova, S. N.; Toukach, F. V.; Cedzynski, M.; Amano, K.; Kaca, W.; Knirel, Y. A. FEBS Lett. 1997, 411, 221-224.

13. Vinogradov, E.; Bock, K. Carbohydr. Res. 1999, 320, 239-243.

14. Vinogradov, E.; Radziejewska-Lebrecht, J.; Kaca, W. Eur. J. Biochem. 2000, 267, 262-269.

15. Westphal, O.; Jann, K. Methods Carbohydr. Chem. 1965, $5,83-91$.

16. Galanos, C.; Lüderitz, O.; Westphal, O. Eur. J. Biochem. 1969, 9, 245-249.

17. Mizushiri, S.; Amano, K.; Fujii, S.; Fukushi, K.; Watanabe, M. Microbiol. Immunol. 1990, 34, 121-133.

18. Amano, K.; Hatakeyama, H.; Okuta, M.; Suto, T.; Mahara, F. J. Clin. Microbiol. 1992, 30, 2441-2446.

19. Amano, K.; Suzuki, N.; Fujita, M.; Nakamura, Y.; Suto, T. Microbiol. Immunol. 1993, 37, 927-933.

20. Amano, K.; Kyohno, K.; Aoki, S.; Suto, T. Microbiol. Immunol. 1995, 39, 63-65.

21. Amano, K.; Fujita, M.; Suto, T. Infect. Immun. 1993, 61, 4350-4355.

22. Amano, K.; Hayashi, S.; Kubota, T.; Fujii, N.; Yokota, S. Clin. Diagnos. Lab. Immunol. 1997, 4, 540-544.

23. Hitchcock, P. J.; Brown, T. M. J. Bacteriol. 1983, 154, 269-277.

24. Ciucanu, I.; Kerek, F. Carbohydr. Res. 1984, 131, 209217.

25. Kjær, M.; Andersen, K. V.; Poulsen, F. M. Methods Enzymol. 1994, 239, 288-308.

26. Vinogradov, E. V.; Sidorczyk, Z.; Knirel, Y. A. Carbohydr. Res. 2002, 337, 643-649. 